\title{
REDES EDUCATIVAS NO CONTEXTO DA CIBERCULTURA: CRIANÇAS DE/NO TERREIRO TRANÇANDO SEUS SABERES
}

\author{
Luzineide Miranda Borges ${ }^{1}$ \\ Marta Ferreira da Silva ${ }^{2}$
}

\begin{abstract}
RESUMO: Para compreender qual é o lugar da infância e como as crianças crescem e se desenvolvem em sua comunidade de origem é preciso olhar atento, ouvido à espreita e muito tempo sentada ou pulando com elas. Este artigo é fruto de 10 anos de pesquisa; dormindo e acordando com as crianças de candomblé fomos percebendo que elas crescem entre adultos, correndo, pulando, brincando e protagonizando o seu cotidiano e nas redes sociais digitais dão visibilidade as suas vivencias a partir das suas narrativas digitais: fotografias, vídeos e comentários. Neste texto apresentamos os desafios dessas crianças e suas mães na luta contra o racismo religioso no contexto da cibercultura. O toque epistemológico e metodológico foi possível a partir do nosso encontro com a epistemologia ancestral e a concepção de criança e infância.
\end{abstract}

Palavras-chave: Redes Educativas. Crianças. Epistemologia Ancestral. Cibercultura.

\section{EDUCATIONAL NETWORKS IN THE CONTEXT OF CYBERCULTURE: CHILDREN FROM / IN THE TERRITORIAL BRAIDING THEIR KNOWLEDGE}

\begin{abstract}
In order to understand the place of childhood and how children grow and develop in their community of origin, it is necessary to look attentively, listen to the lurking and long sitting or jumping with them. This article is the result of 10 years of research; sleeping and waking up with the children of candomblé, we have noticed that they grow up among adults, running, jumping, playing and
\end{abstract}

\footnotetext{
${ }^{1}$ Doutora em Educação na Universidade do Estado do Rio de Janeiro (UERJ). Professora Adjunta da Universidade Estadual de Santa Cruz - Ba. E-mail: neide.luzi@gmail.com

2 Pedagoga e Historiadora. Doutoranda em Educação Unicamp. Bolsista CAPES. E-mail: 14martaferreira@gmail.com
} 
protagonizing their daily life and in the digital social networks give visibility their experiences from their digital narratives: photographs, videos and comments. In this text we present the challenges of these children and their mothers in the fight against religious racism in the context of cyberculture. The epistemological and methodological touch was possible from our encounter with the ancestral epistemology and the conception of children and infants).

Keywords: Educational Networks. Children. Ancestral Epistemology. Cyberculture.

\section{REDES EDUCATIVAS EN EL CONTEXTO DE LA CIBERULTURA: NIÑOS DESDE / EN EL TERREIRO CELEBRANDO SU CONOCIMIENTO}

RESUMEN: Para comprender cuál es el lugar de la infancia y cómo los niños crecen y se desarrollan en su comunidad de origen es necesario mirar atento, oír el acecho y mucho tiempo sentada o saltando con ellas. Este artículo es fruto de 10 años de investigación; durmiendo y despertando con los niños de candomblé fuimos percibiendo que ellas crecen entre adultos, corriendo, saltando, jugando y protagonizando su cotidiano y en las redes sociales digitales dan visibilidad sus vivencias a partir de sus narrativas digitales: fotografías, vídeos y comentarios. En este texto presentamos los desafíos de esos niños y sus madres en la lucha contra el racismo religioso en el contexto de la cibercultura. El toque epistemológico y metodológico fue posible a partir de nuestro encuentro con la epistemología ancestral y la concepción de niño e infancia.

Palabras clave: Redes Educativas. Niños. Epistemología Ancestral. Cibercultura.

\section{Introdução}

As religiosidades de matriz africana na contemporaneidade precisam lidar com questões que Ihe são muito caras - segredos, pouca exposição, resguardar-se. Em tempos de redes sociais digitais, essas questões sofrem ressignificações nesses espaços e tempos de memórias ancestrais. Imagens que se restringiam aos adeptos do candomblé, hoje povoam as redes sociais digitais, tendo acesso pessoas ligadas ao candomblé e pessoas que desconhecem qualquer aspecto dele. 


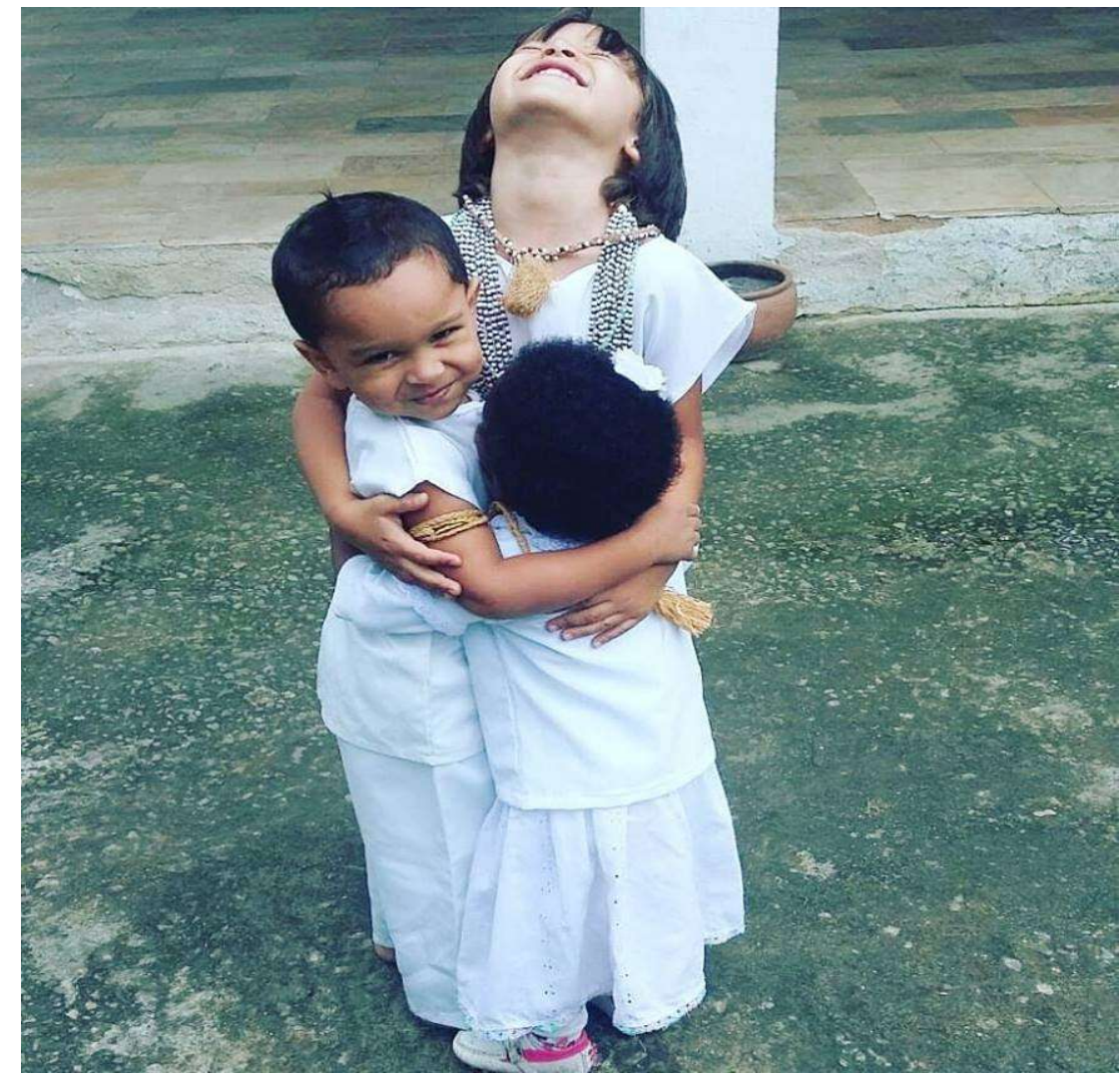

Figura 1 - Dofono ${ }^{3}$ ti Ogum, Dofono ti Șangò, Dofona ti Ewá. Fonte: Arquivo pessoal do terreiro.

Nesse ponto, se instaura nossa preocupação neste ensaio - como pensar as exposições nas redes sociais de uma religiosidade que por ser ligada aos escravizados, aqui no Brasil, carregando marcas profundas de racismos que por séculos justificaram a escravização, e na contemporaneidade contribuem para sua manutenção e principalmente, como pensar estas relações quando se trata de crianças e jovens iniciados no candomblé. Sensíveis à questão por sermos praticantes do candomblé e/ou ter filha praticante, temos uma fala de dentro, de quem vivencia os cotidianos do terreiro e as implicações de sermos candomblecistas em espaços outros, principalmente no espaço acadêmico - tema para outro ensaio. Nossa escrita se situa no que somos - mulheres, negras, mães, candomblecistas, professoras, pesquisadoras,

\footnotetext{
${ }^{3}$ Nome utilizado para determinar o mais velho do grupo iniciado ou do iniciado sozinho.
} 
escrevendo entre o Rio de Janeiro e a Bahia. Nossas discussões, reflexões e escritas vêm impregnadas de nossas experiências de ser e estar no mundo.

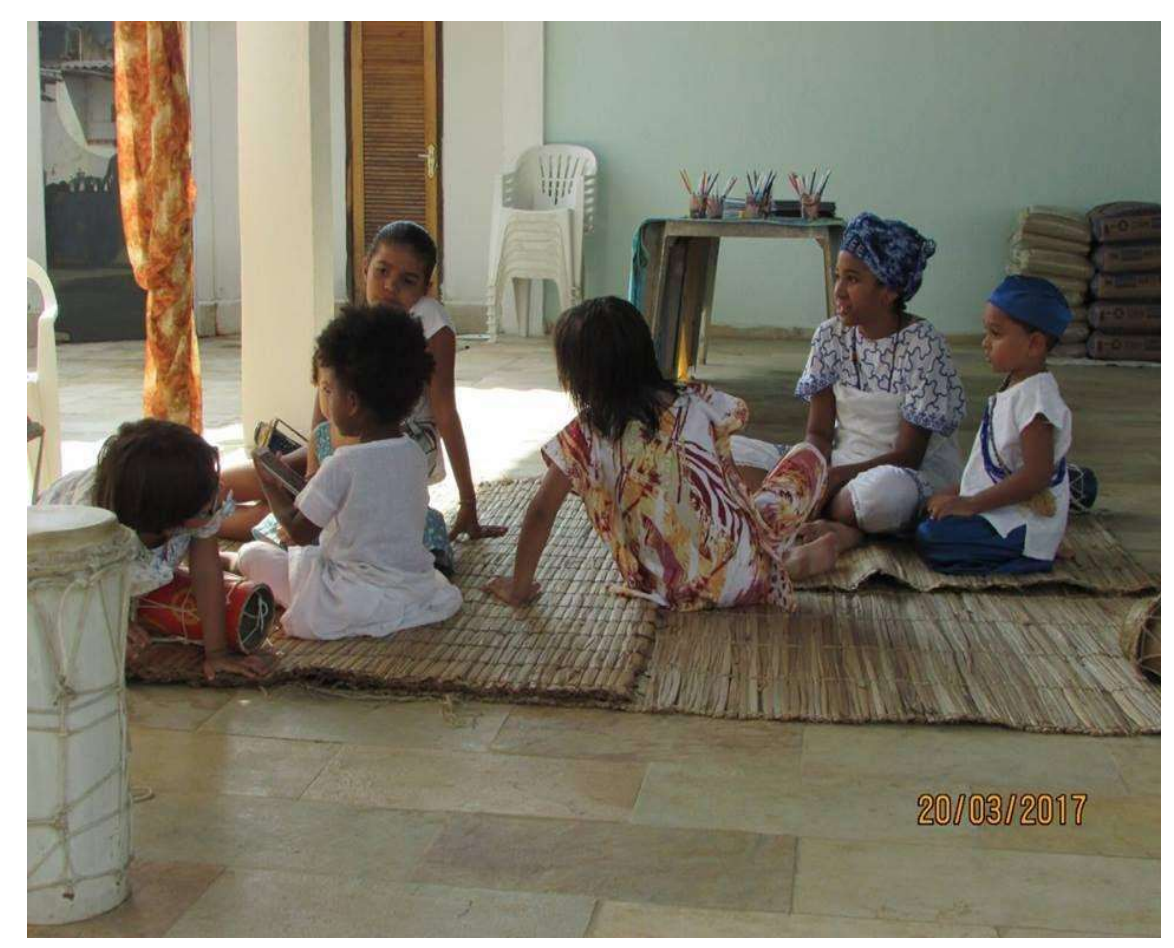

Figura 2 - Crianças do terreiro em atividades de contação de histórias de orișá. Fonte: Janete Bessa ti Ayrá).

Com a publicação em uma rede social, criticando a ex-esposa, lamentando o cabelo raspado da filha, uma avalanche de comentários seguiram a postagem pública, muitos criticando a atitude da mãe em levar sua filha ainda criança para uma religião, não oferecendo a oportunidade de escolha para quando estivesse mais velha, e, portanto, segundo a maioria dos comentários, conseguisse compreender e fazer a sua opção religiosa. Em contrapartida a esses comentários, vieram os que chamavam a atenção para a falta de coerência nas falas, já que nas outras religiosidades não ligadas às de matriz africana, as crianças e jovens também passam por rituais de iniciação e pouco se veem comentários contrários, como no caso de batismos, apresentações nas igrejas sempre em crianças ainda na tenra idade. Então o que moveria tamanha 
repercussão com o ritual do candomblé em crianças?

Um ponto citado anteriormente deve ser considerado - os racismos religiosos infligidos nas religiosidades de matriz africana; a tentativa de compreensão a partir de uma lógica ocidental das práticas afrodiaspóricas também dificultam; o olhar construído para enxergar algo como ruim, macabro, primitivo e não como práticas e modos de perceber e estar no mundo sob outra perspectiva, acaba por trazer um estigma ao que não se encaixa aos padrões ocidentais da chamada "civilidade".

\begin{abstract}
Retomando, podemos afirmar que os candomblés são um modo de vida que contêm, em seu interior, uma forma de espiritualidade, tendo a comunidade em formato familiar, como eixo organizativo da autoridade coletiva e constituidor da identidade pessoal, a ancestralidade como modo de gerenciar a memória, a história e projetar o futuro e a natureza como unidade/totalidade que, inserida em um continuum com a comunidade que permite tomar decisões sobre a estrutura da realidade, pensando em uma interdependência geral entre os elementos que constituem nossa experiência. Para esse modo de vida, um incessante movimento gerencia a existência e todas as relações entre tudo o que existe (FLOR DO NASCIMENTO, 2018, p. 506).
\end{abstract}

Considerando como primeiro passo para tentarmos avançar seria mudarmos da cosmovisão para a cosmo percepção, como afirma Oyewumi (1997), pois os saberes aprendidos, repassados, ressignificados nesses espaços e tempos para crianças, jovens e adultos são de outra dimensão, precisamos ir além do olhar, devemos sentir cheiros, cores, texturas, ventos, cantos, danças, itàn/histórias de orixá, arrepios etc.; existe uma memória ancestral reavivada por meio dos sentidos. Não é preciso o "ver para crer", é preciso sentir com o corpo.

O que analisamos das falas do nosso povo de terreiro e das próprias crianças e jovens dos candomblés é que conhecer e compreender o que é a sua religião, os sentidos das ritualísticas fortalece e dá estrutura para passarem por esses momentos de tensão e até mesmo de violência relacionados ao que está intimamente ligado à afrodiáspora. Ao nos depararmos com postagens, imagens, comentários que fazem 
duras críticas à inserção de crianças nos rituais de candomblé, percebemos que os processos de colonização fizeram e continuam fazendo muito bem seu trabalho de manutenção de uma ordem em que as lógicas e os modos de vida diferentes aos modelos ocidentais são duramente criticados e considerados negativos para a sociedade.

Comentários como: "criança não pode ser iniciada porque não sabe escolher religião", "absurdo enfiar criança nessas coisas", "a mãe precisa ser responsabilizada por esse absurdo"; são exemplos de como religiosidades como os candomblés, originárias dos povos negros escravizados continuam com a marca racial forte, impregnada nos olhares de fora. Em contrapartida, tivemos várias publicações, principalmente de mães candomblecistas, com fotos de suas crianças iniciadas, com suas roupas, fios de contas, panos de cabeça, virados de santo (transe para os ocidentalizados), em rituais e com depoimentos em defesa da liberdade religiosa e chamando a atenção para os batismos e rituais outros ligados às demais religiosidades que envolvem crianças e que não vimos e/ou vemos nenhuma manifestação contrária ou de repúdio.

As crianças de terreiro brincam de correr o tempo todo nesses espaços e tempos, sentem a energia das suas ancestralidades. Temos o privilégio, nós dos cotidianos do terreiro, durante as funções (como nos referimos aos momentos ritualísticos), de ver nascer fisicamente, de ver nascer para a ancestralidade nos rituais de iniciação do candomblé. Derramamos nos seus orí/cabeças a primeira água ritual, entregamos os primeiros presentes ancestrais. Crianças que vemos crescer nos cotidianos do/no candomblé; que correm nas brincadeiras de pique, que correm ao sentir a energia circulante do seu orixá. Então, os comentários das redes sociais, negativando as religiosidades de matriz africana mostram um desconhecimento de religiosidades outras, para além das cristãs ocidentais e seus caminhos de 
desconsideração ao que não responde aos padrões eurocentrados.

As contradições sobre idades para o ingresso em rituais religiosos também demonstram e confirmam o que chamamos a atenção no início do texto para os racismos religiosos, tendo em vista que só os rituais afrodiaspóricos são comentados de forma pejorativa e como prejudicial aos menores de idade. Até mesmo nos ambientes escolares, principalmente, públicos, percebemos essa naturalização das religiosidades cristãs ocidentais, como por exemplo, páscoa, ação de graças, natal etc. Quando ocorre a tentativa de implementação das legislações 10639/2003 (BRASIL, 2003) ou 11645/2008 (BRASIL, 2008), com inserção no currículo de conteúdos ligados a africanidades, afrodiáspora e/ou civilizações indígenas, percebemos, na maioria das vezes, resistências, recusas por parte de responsáveis e até mesmo das equipes de gestão e do corpo docente, principalmente no que diz respeito às religiosidades, que possuem uma riqueza social histórica na maioria dos casos deixadas de lado. Segundo Flor do Nascimento (2018, p. 502-503),

Essas experiências receberam diversos nomes em vários lugares de nosso país; entre elas, as mais conhecidas são os Candomblés, que surgiram basicamente na Bahia e Rio de Janeiro, os Tambores no Maranhão, o Xangô, no Recife e o Batuque no Rio Grande do Sul. Essas "religiões" diferem-se de outras que também têm elementos africanos, ameríndios e europeus, como a Umbanda, o Terecô, a Jurema entre outras, por buscarem recriar um contexto que se aproximasse o tanto quanto possível das ancestralidades africanas, mantendo línguas, modos de organização comunitária, valores, crenças, saberes e práticas que foram herdadas e recriadas desde os referenciais desses povos africanos, embora articulados com elementos não africanos como, por exemplo, os saberes indígenas sobre as plantas de nossa região, fundamentais para as práticas dos candomblés.

Entendemos que essas tensões provocam silenciamentos e invisibilidades dos alunos negros, de etnias indígenas e/ou ligados as religiosidades de matriz africana, ferindo a laicidade do estado e da escola pública. A exposição nas redes sociais dessa problemática aumenta consideravelmente nossas preocupações com as crianças e 
jovens nos meios sociais nos quais estão inseridos.

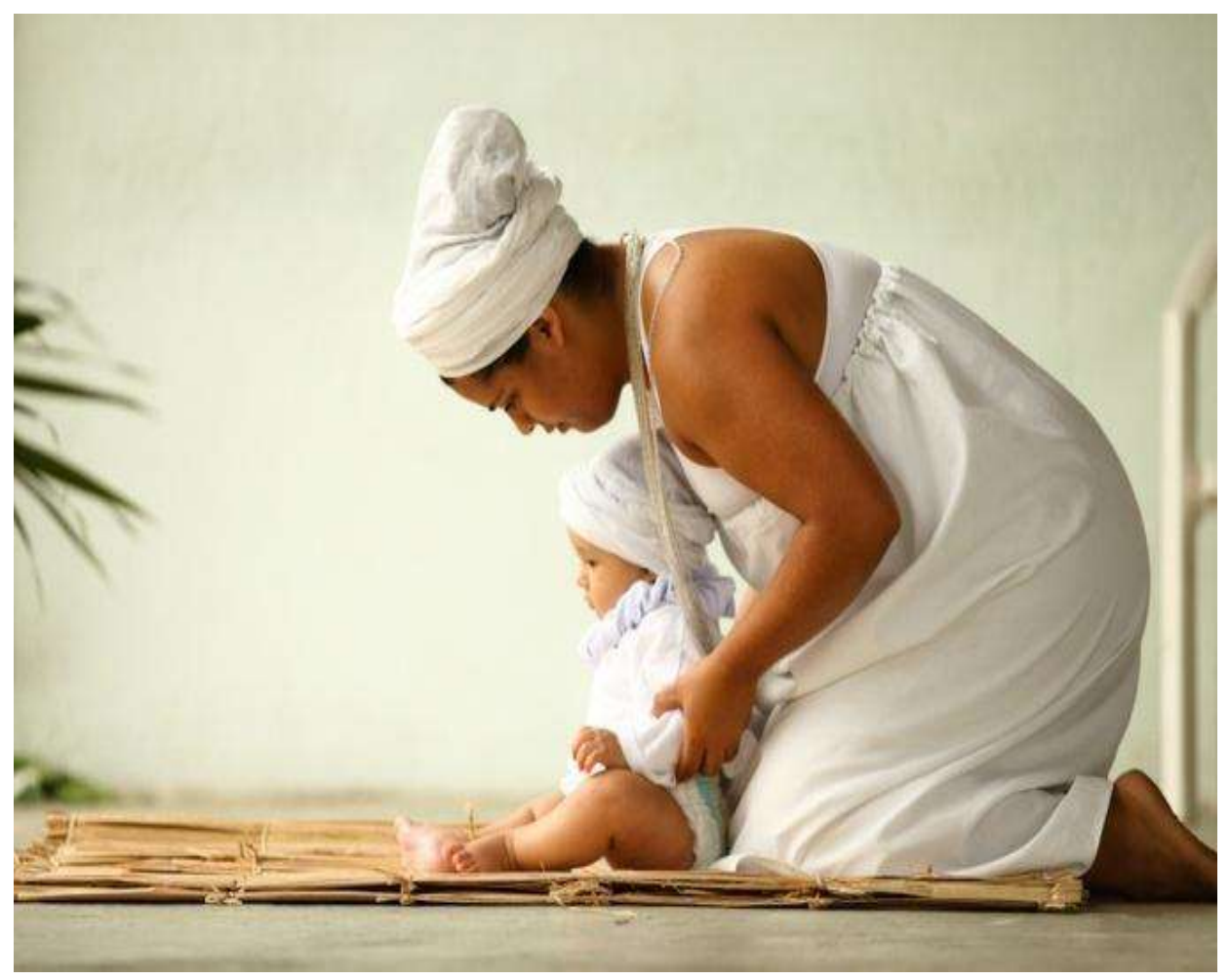

Figura 3 - Dofono ti Șangò no período de sua iniciação, auxiliado por sua prima. Yasmine ti Yemonjá. Fonte: Luciana Serra/Luciana Paz

Como lidar com essa diversidade sem sermos desrespeitosos e desrespeitados? Como circular nos espaços e tempos sem sofrer agressões que não fazem sentido, por não comporem nossos repertórios de dialogismos sociais? Essas questões não possuem respostas imediatas, mas precisam ser lembradas cotidianamente para não reforçarmos intolerâncias e violências sociais.

\section{Ser criança de terreiro}

Segundo Flor do Nascimento (2018, p. 592): “[...] a criança para o pensamento tradicional africano é a marca da continuidade, uma expressão da ancestralidade. Ela nem é nova e nem começa. Ela segue. Mas não segue monotonamente. Ela segue em 
inversões, deslocamentos, fissuras".

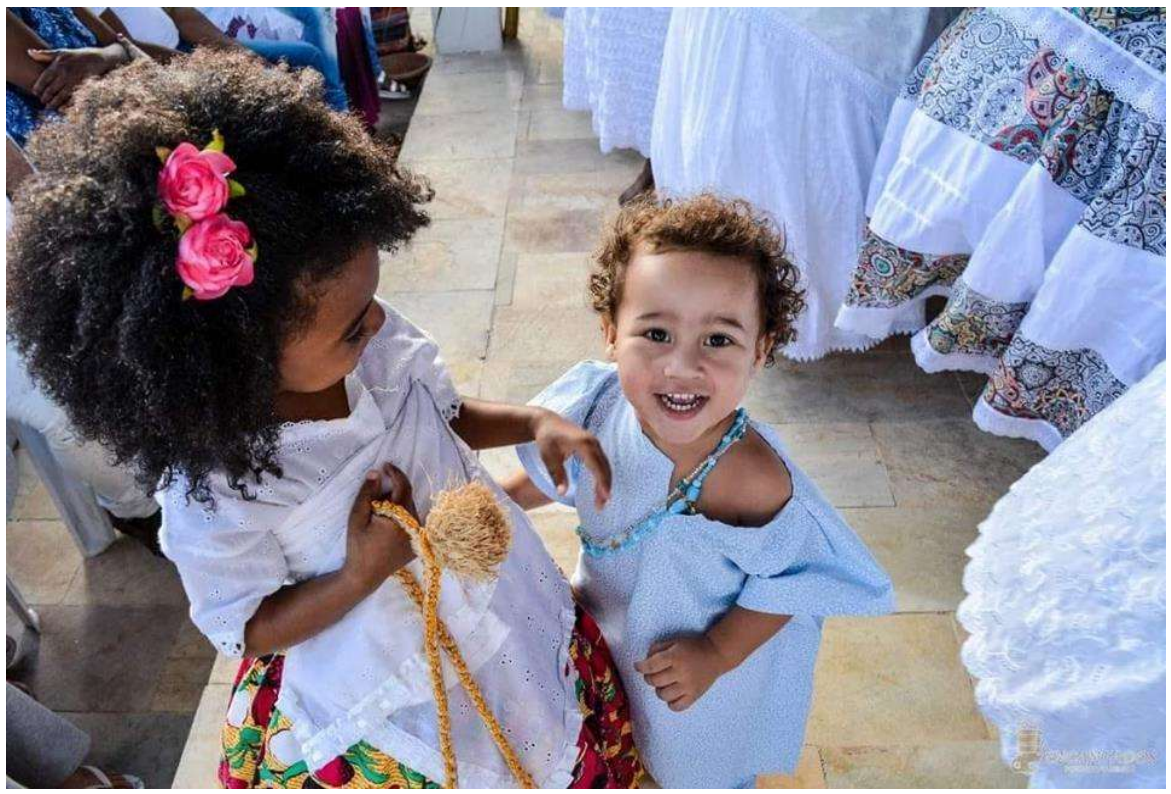

Figura 4 - Dofona ti Ewá e Ogan ti Oșóssè.

Fonte: Patricia Muniz/Encantados Fotos.

Dofono ti Șangò, iniciado aos 4 meses, que aos 5 anos hibridizava os desenhos animados com orixá; ama Șangò tanto quanto ao Homem Aranha são seus heróis. Hoje, aos 8 anos de idade, sente orgulho do terreiro que faz parte com sua família e faz planos para ajudar seu pai de santo quando ficar maior e assim declara.

Fui feito com 4 meses. O barracão é maravilhoso pra todos nós. Os orôs ${ }^{4}$ são lindos! Babá ${ }^{5}$ explica tudo muito bem! Sabia que Babá que descobriu que eu estava na barriga da minha mãe? O Babá me salvou, quase que eu morro, mas ele me salvou. Ele me ensinou muitas coisas, pra nós. Adoro ele! Ele é um bom pai de santo! Eu adoro meu barracão! Ele é lindo! Muitas coisas eu vou fazer lá quando eu crescer. Eu amo meu barracão! (Dofono ti Șangò, 8 anos).

Dofona ti Ewá, iniciada aos 6 meses, com seu ilá/brado "Kiú", olhos cerrados, pulos, brincando de receber o orixá Oșóssè; ou dançando na frente do espelho,

\footnotetext{
${ }^{4}$ Rituais.

${ }^{5}$ Como a liderança do terreiro é chamado comumente pelos frequentadores; o pai de santo.
} 
cantando as rezas proferidas durante os banhos ritualísticos; ensinando seus irmãos menores, ainda bebês, como se engatinha, que é preciso comer. Hoje, com 5 anos de idade se considera mais velha e responsável pelos bebês.

Eu gosto de ir no Așé, mas não gosto não - é longe demais! Eu e a Tatá brigamos! Gosto de correr, de brincar, de pular, de ver a Helena. Gosto de bori, porque tem camarão. Gosto de comer no Așé. Gosto da folha ${ }^{6}$ (Dofona ti Ewá, 5 anos).

Crianças, como Dofono ti Ogum, que explicam como será a festa de seu orixá, as roupas e outros ancestrais convidados para dançar com ele; crianças e suas brincadeiras com seus idés/pulseiras prateados, que distraímos durante a festa de seu orixá para não correr direto atrás dos irmãos a brincar; que pede colo para passar o dedo no bolo do ritual de seu orixá, como a Dofona ti Yemonjá. Pequenos que amam Yemonjá e a chamam de minha mãezinha e explicam para as pessoas que não são do candomblé que sua mãezinha é a dona de todos os peixinhos do mundo.

São crianças que emocionam a todos ao brincar, dançar e sentir a energia do orixá. Temos o privilégio de presenciar e participar desses momentos de lindezas, sensibilidades e compreensões variadas, por parte das crianças nos cotidianos dos terreiros, com suas brincadeiras, desenhos, ajudando no ajeum/comer, dando omí/água aos menores, chamando atenção nas artes e bagunças, bagunçando junto. Porque ser de Așé, ser candomblecista é isso. Estamos em comunidade, na coletividade, nos cotidianos com todas as nossas atividades fora do terreiro, mas acreditando que estamos contribuindo para reverberar por meio desses pequenos jovens candomblecistas, modos de vida outros.

\footnotetext{
${ }^{6}$ Ritual de cantar usando os nomes das folhas. 


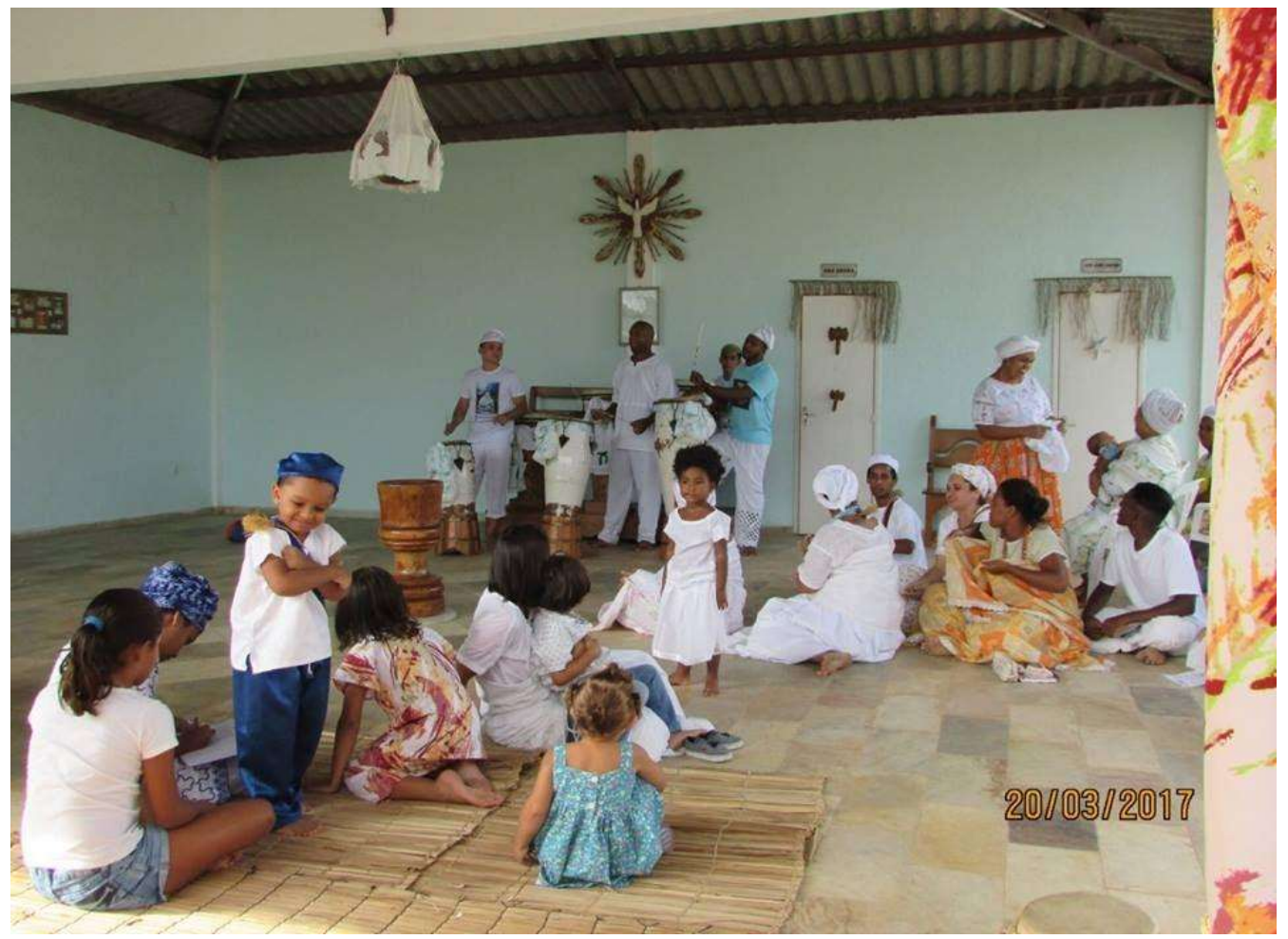

Figura 5 - Oficina de toques e cantos realizada no terreiro com participação das crianças, jovens e adultos.

Fonte: Janete Bessa ti Ayrá.

\section{O terreiro e sua importância na reconstrução dos laços de parentesco para crianças de axé}

Se uma criança cresce achando que sua mãe e seu pai são sua única comunidade, quando tem um problema e os pais não conseguem resolvê-lo, ela não tem ninguém a quem recorrer (SOMÉ, 2007, p. 41). O povo de terreiro é um povo que escolheu pertencer a uma comunidade religiosa da qual se identifica pela sua capacidade de acolhida, partilha de afetos e cuidados, alguns por questões espirituais, outros pelo desejo de pertencer a uma família mais extensa, pautada na responsabilidade de todos por todos. É uma comunidade que partilha de alguns desejos e saberes que, durante anos, os processos de colonização vêm tentando destruir. Uma das questões defendidas pelo povo nagô a muito custo é o sentimento 
de pertencimento, de fazer parte de uma família escolhida, cada pertencente do axé, escolheu, por algum motivo particular, estar dentro do axé. Para uns foi a doença, para outros foi o desemprego, a falta de família congênita também está como uma dessas escolhas. Há quem quis ser candomblecista por curiosidade pura, foi fazer uma pesquisa e de lá não voltou mais, permaneceu lá (PÓVOAS, 2007).

Esse sentimento de pertencimento, "Eu sou do axé!", está cada vez mais presente entre os que vivem nessas comunidades. Outro sentimento desse pertencimento é o sentimento de irmandade. Ninguém vive sozinho. É no coletivo que nos tornamos mais humanizados e, como irmãos e irmãs, precisamos aprender a dividir. Dividir o ajeum, dividir as angústias mundanas, partilhar o afeto no abraço trocado e, muitas vezes, oferecer o nosso cobertor nas noites de frio e "construir comunidades em que se possa confiar uns nos outros" (SOMÉ, 2007, p. 44).

Apesar de frequentar o terreiro de candomblé, desde quando tinha oito anos de idade, em 2011, Layza Miranda/Pé Lokè (na fotografia acima, ela está à direita), mudou-se para Ilhéus/BA com irmã mais velha e sua mãe, que havia passado no concurso público e encontrou no llê Axé Odé Omopondá Aladê ljexá amparo, cuidado e afeto para seguir seu reencontro ancestral. Pé Lokè foi iniciada em 2015, aos 12 anos, e hoje é conhecida como Loyá Pè Lokè e é a ya Tabexi ${ }^{7}$ do terreiro. No primeiro ano de escola, na nova cidade, no Dia das Crianças, Pé Lokè, com apenas 8 anos, me disse “Mãe, eu não quero brinquedo, eu não quero viajar, eu só quero que a senhora alise meus cabelos, não aguento mais meus colegas me chamando de macumbeira do cabelo de piaçava ". Não foi fácil digerir esse pedido. Não era um pedido, era uma denúncia de que na escola a sua estética negra e a sua religiosidade eram motivos violência e que ela estava perdendo a sua autoestima.

\footnotetext{
${ }^{7}$ É a pessoa que é iniciada na religião e tem como função cantar para o orișá.
} 


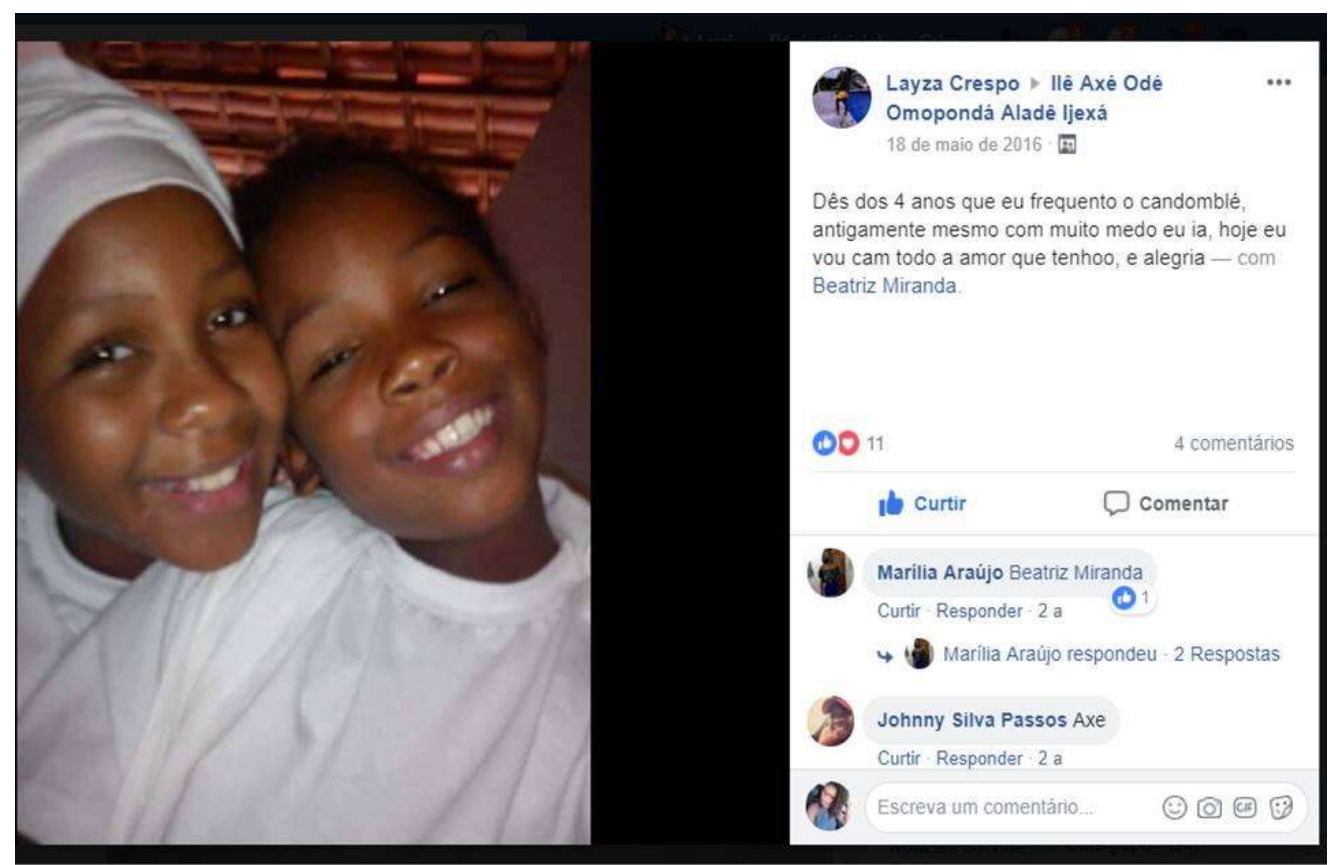

Figura 6 - Publicação no grupo do terreiro em rede social.

Fonte: Grupo fechado do llê Axè Odé Omopondá Aladè ljexá no Facebook, 2015).

Gomes (2002), em “Corpo e cabelo como símbolos da identidade negra" e Hooks (2005), com "Alisando nossos cabelos", me ajudaram a compreender como a estética das meninas negras é o primeiro desafio a ser enfrentado em idade escolar. "Se antes a aparência da criança negra, com sua cabeleira crespa, solta e despenteada, era algo comum entre a vizinhança e coleguinhas negras, com a entrada para a escola essa situação muda. A escola impõe padrões de currículo, de conhecimento, de comportamentos e de estética" (GOMES, 2002, p. 45).

Quando levei essa questão para mãe Darabi, ela me disse: "deixa alisar, um dia elas voltam". E fomos encontrando no terreiro força para caminhar. Em suas páginas no Facebook, ela fala das violências sofridas como menina negra, que voltou a usar seu cabelo crespo natural, e candomblecista. Ela diz: "não quero ser tolerada, e sim respeitada". Perguntei como se sentia diante de tantas agressões, ela respondeu balançando os ombros: "tou nem aí, sirvo o meu orixá, amo o meu terreiro e esse povo 
nem sabe do que estão falando". Lamentavelmente, o povo de axé segue lutando contra o racismo religioso.

Percebo que o egbé preserva o modo de viver bem próximo da descrição que Somé faz da sua aldeia, por um lado devido à concepção de família estendida, por outro, por compreender que aquele/a pertencente à determinada aldeia faz parte da família. Portanto, a identidade é construída a partir desses entrelaçamentos consanguíneos e de vida comunitária. Na Aldeia Dagara, descrita por Somé (2007), eles não conhecem a concepção de tio e tia, muito menos de primos e primas. Para eles, toda tia é uma mãe e todo primo é um irmão. Assim, uma criança escolhe em que casa quer ficar e lá pode permanecer por dias, meses e até anos e as tias não se incomodam com sua presença ou se sentem menos responsáveis pela sua formação, "é preciso toda uma aldeia para manter os pais são" (SOMÉ, 2007, p. 44).

Pè Lokè, como é conhecida dentro do terreiro, é a ativista digital mais atuante do Terreiro, quando ela diz "e não nego minha origem", ela chama a atenção para as táticas que muitos candomblecistas usam para seguirem invisíveis e não sofrerem o racismo religioso. Além de várias postagens que ela faz em seu perfil pessoal no Facebook, ela tem uma página com a sua função no terreiro com mais de 4.500 seguidores. Com ela fui compreendendo que empoderamento é processo, é vivência cotidiana de fortalecimento em rede e que é preciso muitas rodas de diálogos sobre a nossa cultura, sobre os processos de lutas das mulheres negras na diáspora e nos países africanos para que tenhamos forças para resistir contra os processos colonizadores presentes na contemporaneidade.

As redes sociais digitais foi o abebé ${ }^{8} /$ espelho, que Loyá Pè Lokè utilizou para afirmar a sua negritude. Mas também foi por meio desse mesmo espelho que ela se via negada nas páginas do instagram e do Facebook que seguia, quase não existia

\footnotetext{
${ }^{8}$ É paramenta utilizado pela Orișá Oxum e iemanjá.
} 
representatividade da sua cultura, religião e de mulheres negras como ela. Inicialmente, quase não via crianças negras nas redes sociais digitais. Aos poucos começaram a compartilhar as suas fotografias vestidas de roupas de axé e fios de contas. Acolhimentos diversos e múltiplos colaboraram para que ela refizesse sua estética e compreendesse que temos o direito de ter o cabelo que queremos ter e que a cor e a textura dos nossos cabelos serão escolhidas pelas nossas referencias africanas preservadas, cultuadas e ressignificadas nos aquilobamentos contemporâneos produzidos a partir de uma educação identitária e antirracista nos terreiros de candomblé e nas redes socais digitais.

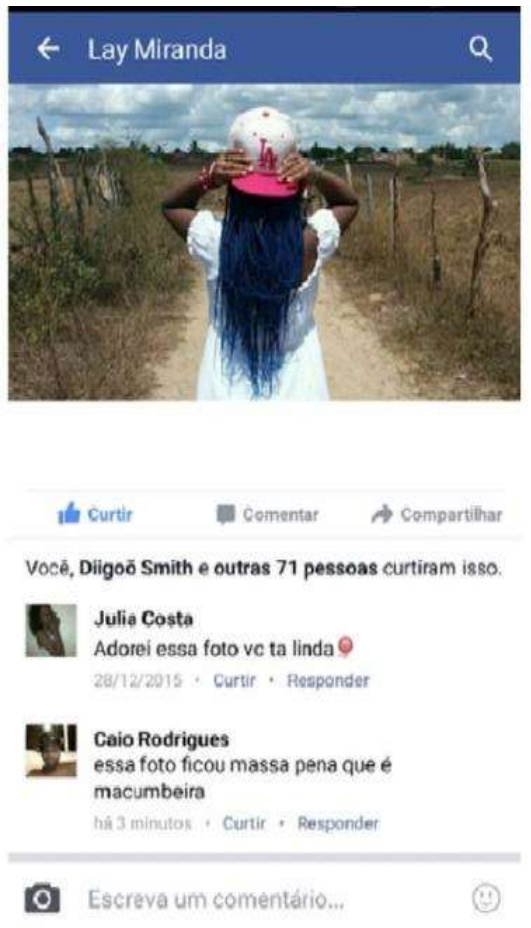

Figura 7 - Perfil e da página de Loyá Pè Lokè, em junho de 2015.

\section{$\leftarrow$ Publicaçōes $\quad$ Q}

\section{Yá Tabexi Ty Oya}

Olha gente me pediram muito pra fazer essa Facebook pra falar só sobre as religióes de matrizes Africanas, entåo se você é evangélico me exclui, pora ninguém vai mudar minha religião, e eu tb não gosto de ficar discutindo. é só vocè adicionar pessoas evangélicas q posta salmo ou coisa de Deus toda hora, eu nunca adicionei ninguém pra ficar chamando pra minha religiäo então parem. E também quem vier atrás de papo de relacionamento ou algo parecido pode exclui tbm, esse meu face năo é pra isso. Irei continuar postando foto de "macumba" sim , irei continuar fazendo vídeos sim, irei continuar com tudo, ninguém precisa vim me dizer nada sobre Deus não.

E simples só excluir

Amo vocês. Okolofe, Motumba

$$
\text { Ih Curtir } \quad \Rightarrow \text { Comentar Compartithar }
$$

00 Alba Gristina Soares e outras 46 pessoas

Eu sou evangélico sim apenas deixei ums versiculos da bíblia para você porque senti no coraçăo de deixar mais nunca falei para

\section{O) Escreva um comentário..}

\section{Roberto Batista}

\section{Fonte: Imagem do perfil de rede social.}

A vida das crianças negras nunca foi fácil. A nossa luta não é só por uma estética afrocentrada, mas também por uma educação que seja construída a partir da nossa 
história contada por nosso povo, que foi apagada dos currículos escolares. Se as crianças negras e brancas brasileiras crescessem num ambiente escolar e familiar que positivasse a cultura africana e afro-brasileira não estaríamos aqui apresentando essas narrativas. Falar das nossas histórias negadas e marcadas por violência é apresentar aos educadores motivações para pensar em produções de conhecimentos interrelacionados com os saberes e fazeres das comunidades de terreiros que desenvolvem trabalhos ancestrais de reontologização das mulheres negras e homens negros que secularmente tiveram a humanidade negada.

A narrativa da Loya Pè Lokè (Miranda), na Figura 7, é um dos inúmeros exemplos que encontramos nas redes sociais digitais, que representa as complexidades ser do axé. São várias postagens em que meninas como ela precisam se defender, se resguardar para ter o direito de viver seu axé. Entre "pena que é macumbeira" e diz que respeita, mas entrega um panfleto com versículo da bíblia numa tentativa de conversão, está a cultura judaica cristã presente em todas as repartições públicas do nosso país, que se diz laico, mas que agressivamente nos diz que quem não é 'cristão, boa gente não é'.

Os sinais diacríticos do povo de axé vão colorindo e invadindo as redes sociais digitais levantando questionamentos, produzindo o que Mirzoeff (2016) denomina como afrovisualidade ou o direito de olhar e ser visto/a. Desfazendo o olhar racista produzido pelas mídias de massa que sataniza e demoniza as religiões de matrizes africanas como o candomblé e a umbanda, as crianças e suas mães, ao produzirem as suas narrativas digitais a partir da cotidianidade de axé, colaboram na luta contra o racismo religioso e direito de ver e ser vista a partir das suas vivências culturais. Apesar do avanço do obscurantismo e das religiões neopentecostais, as crianças de axé estão a dizer: "nenhum passo a menos!" e espalham nas suas timeline a força ancestral que faz com que dancem, cantem e cuidem da sua autoestima como criança de axé, que 
cuida uma das outras e também busca alimento para sua subjetividade e seu viver dentro e fora do terreiro.

\section{Inconclusão de uma trilha ainda em construção}

Com o abebè de mãe Oxum a mirar as nossas demandas cotidianas como mulheres negras e do axé, seguimos atravessadas pela força da guerreira africana que nos ensina todos os dias que, se o racismo é uma estrutura capitalista de negação da nossa humanidade, ela nos dará condições subjetivas (a força para caminhar) e objetivas (uma família de axé), que nunca nos deixará sozinhas nessa sociedade organizada a partir de uma compreensão mercadológica individualista. São essas compreensões que nos levaram a olhar esses saberes como fundantes na constituição do ser criança de axé preservada nos terreiros de candomblé.

A epistemologia do pertencimento tem como pauta de discussão e reivindicação o direito de existir na produção do conhecimento acadêmico como conhecimento emancipador pautado na cultura africana, produzido na África e na diáspora, forjado pelos sujeitos como autores da sua própria história (BORGES, 2017). O povo nagô não são filhos do diabo nem cultuam demônio como ouvimos nos programas de TV, em horários de grande audiência. O nosso presente é construído a partir das bases culturais produzidas na preservação da nossa memória de reis e rainhas, que os nossos ancestrais nos presentearam, mas que foi 'roubada' no processo de colonização.

Os nossos saberes ancestrais superam a dor e o sofrimento da travessia transatlântica, a solidão e do desencaixe familiar com a separação dos familiares nas senzalas. Deram força e garra para fugirmos das senzalas e depois reconstruirmos nos quilombos e, hoje, nos terreiros de candomblé, os nossos valores civilizatórios, históricos e culturais. Ainda estamos longe das benesses dos nossos direitos humanos, temos muita luta pela frente. Mas nos enche de esperança ver uma postagem em que 
povo de axé se posiciona como pertencente de uma religião que historicamente foi/é perseguida.

Nesse ciberxirê com pequenas dofonas, pequenos dofonos, com meninas senhoras que cantam na língua ancestral, somos vento, somos água doce, somos água salgada, cantamos para as folhas, brincamos o xirê rememorando e ressignificando saberes herdados de gerações passadas, dançamos ao ritmo de tambores ancestrais, seguindo ordens não adultocêntricas, sendo livres das amarras, castigos, pecados que não fazem parte do nosso repertório religioso. Os nossos saberes ancestrais superam a dor e o sofrimento da travessia transatlântica, a solidão do desencaixe familiar com a separação dos familiares nas senzalas. Deram força e garra para fugirmos das senzalas e depois reconstruirmos nos quilombos e, hoje, nos terreiros de candomblé os nossos valores civilizatórios, históricos e culturais.

\section{Referências}

BORGES, L. M. Facebook e afroreligiosidade: o orunkò e os 'nós' no intercruzamento das redes que nos formam. Odeere, Jequié, BA, v. 3, n. 3, p. 221-250, jan./jun. 2017. Disponível em: http://periodicos2.uesb.br/index.php/odeere/article/view/1579/1362. Acesso em: 17 set. 2017.

BRASIL. Lei no 10.639, de 09 de janeiro de 2003. Altera a Lei n.o 9.394, de 20 de dezembro de 1996, que estabelece as diretrizes e bases da educação nacional, para incluir no currículo oficial da rede de ensino a obrigatoriedade da temática história e cultura afro-brasileira, e dá outras providências. Brasília, DF: jan. 2003. Disponível em: http://www.planalto.gov.br/ccivil_03/leis/2003//10.639.htm. Acesso em: 28 set. 2017.

BRASIL. Lei no 11.645, de 10 de março de 2008. Altera a Lei no 9.394, de 20 de dezembro de 1996, modificada pela Lei oㅡ 10.639, de 9 de janeiro de 2003, que estabelece as diretrizes e bases da educação nacional, para incluir no currículo oficial da rede de ensino a obrigatoriedade da temática "História e Cultura Afro-Brasileira e Indígena”. Brasília, DF: mar. 2008. Disponível em: 
http://www.planalto.gov.br/ccivil_03/_ato2007-2010/2008/lei/l11645.htm. Acesso em: 17 set. 2017.

FLOR DO NASCIMENTO, W. Manifestações afro-brasileiras: cosmopercepções e religiosidades africanas no Brasil. In: KOMINEK, A. M. V.; VANALI, A. C. (org.). Roteiros temáticos da diáspora: caminhos para o enfrentamento ao racismo no Brasil. Porto Alegre: Fl, 2018a. p. 501-518.

- Temporalidade, memória e ancestralidade: enredamentos africanos entre infâncias e formação. In: RODRIGUES, A. C.; BERLE, S.; KOHAN, W. O. (org.). Filosofia e educação em errância: inventar escola, infâncias do pensar. Rio de Janeiro: NEFI, 2018b. p. 583-595.

GOMES, N. L. Trajetórias escolares, corpo negro e cabelo crespo: reprodução de estereótipos ou ressignificação cultural. Revista Brasileira de Educação, Rio de Janeiro, n. 21, p. 40-51, 2002. Disponível em: http://www.scielo.br/pdf/rbedu/n21/n21a03.pdf. Acesso em: 20 jun. 2017.

HOOKS, B. Alisando o nosso cabelo. Revista Gazeta de Cuba, Unión de escritores y Artista de Cuba, jan./fev. 2005. Tradução: Lia Maria dos Santos. Disponível em: http://historiaemprojetos.blogspot.com/2009/05/alisando-nossos-cabelos.html. Acesso em: 17 set. 2017.

MIRZOEFF, N. O direito a olhar. Educação Temática Digital, Campinas, v. 18 n. 4, p. 745-768, out./dez. 2016. Disponível em:

https://periodicos.sbu.unicamp.br/ojs/index.php/etd/article/view/8646472/14496. Acesso em: 17 set. 2017.

OYEWUMI, O. The invention of women: making an African sense of western gender discourses. Minneapolis: University of Minnesota Press, 1997.

PÓVOAS, R. C. Da porteira para fora: mundo de preto em terra de branco. 1. ed. Ilhéus: Editus, 2007.

SOMÉ, S. O espírito da intimidade: ensinamentos ancestrais africanos sobre maneiras de se relacionar. 2. ed. São Paulo: Odysseus Editora, 2007.

Enviado em: 02/06/2019

Aprovado em: 26/09/2019 